
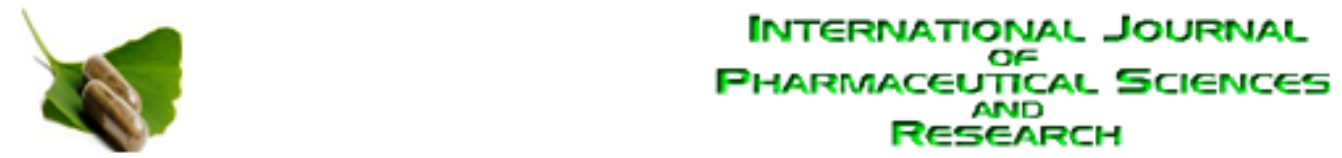

Received on 27 September, 2011; received in revised form 13 November, 2011; accepted 17 January, 2012

\title{
FORMULATION AND EVALUATION OF FAST DISSOLVING TABLETS OF ACETAMINOPHEN
}

\author{
Abhay Kumar Mourya* ${ }^{1}$, Sunil K. Prajapati ${ }^{1}$, S.K. Jain ${ }^{1}$, Ajay Kumar ${ }^{2}$, Atul Kumar Thakran ${ }^{3}$ and Shashi Alok ${ }^{1}$ \\ Institute of Pharmacy, Bundelkhand University, Jhansi, Uttar Pradesh, India \\ Institute of Pharmaceutical Science, Guru Ghasidash University, Bilaspur, Chhattisgarh, India \\ College of Pharmacy, IFTM, Moradabad, Uttar Pradesh, India
}

\section{ABSTRACT}

Keywords:

Optimized formulation,

Poor compression properties,

Combination ratios,

Superdisintegrant,

Compressibility characteristics

Correspondence to Author:

Abhay Kumar Mourya

Institute of Pharmacy, Bundelkhand

University,Jhansi, Uttar Pradesh, India
The present research work has been carried out for an optimized formulation of co-processed directly compressible vehicles in the preparation of the Acetaminophen mouth fast dissolving tablets (MFDTs). Acetaminophen was chosen due to its poor compression properties. Dicalcium Phosphate(DCP) was incorporated in the neutralized aqueous starch dispersion to prepare co-processed excipient. Co-processed direct compressible DCP and Starch used as co-processed excipient were taken in good formulation ratio such as (25:75) and Cross Povidone used as superdisintegrant. The effects of other superdisintegrants were studied in the best formulation F5. Formulation F5 was found to be optimum compressibility characteristics hardness $3.62 \pm 0.40$ to $4.68 \pm 0.31 \mathrm{~kg} / \mathrm{cm}^{2}$ with fast disintegration $(10 \mathrm{sec})$ compare to other formulations
INTRODUCTION: A MFDTs is a tablet that dissolves or disintegrants in the oral cavity without the need of water or chewing ${ }^{1}$. Oro dissolving tablets are MFDTs which dissolves or disintegrate in oral cavity within a minute with significantly increased bioavailability than those observed from the conventional tablet dosage forms. Several approaches have been employed to formulate fast dissolving tablets involving tablet moulding, freeze-drying, sublimation, spray drying, disintegrants addition-direct compression and use of sugar based excipients ${ }^{2}$.

Out of these, disintegrants addition-direct compression is well known technique where disintegrants help to facilitate drug dissolution and consequently improve the bioavailability. Disintegrants that are effective at lower levels and help in rapid disintegration is of great importance in formulations by direct compression. Direct compression, over and above eliminates exposure of heat and moisture during processing and is more economical process.
Ideal directly compressible adjuvant must exhibit good flow ability and compatibility. No single adjuvant is likely to possess all the ideal characteristics. For this reason, the current trend in industry is to use multifunctional co-processed excipients ${ }^{3}$.

Co-processing can be defined as combining two or more established excipients by an appropriate process. Co-processing is based on the novel concept of two or more excipients interacting at the sub particle level, the objective of which is to provide a synergy of functionality improvement as well as masking the undesirable properties of individual ${ }^{4}$.

Present investigation was aimed to prepared Acetaminophen mouth fast dissolving tablets (MFDTs) using co-processed direct compressible vehicles in different ratios employing direct compression technique to improve hardness, reduce disintegration time as well as to achieve satisfactory mouth feel. Acetaminophen an important analgesic and antipyretic 
agent, was chosen for the present work due to its poor compression properties, and therefore requires a binding agent among other excipients to form good quality tablets. These are also called melt-in-mouth tablets, repimelts, porous tablets, oro-dispersible, quick dissolving or rapid disintegrating tablets.

MATERIALS: The drug Acetaminophen U.S.P. was obtained as a Gift sample from Green Pharma, Ahmadabad and Sodium saccharine, Wheat starch I.P., Di-calcium phosphate, Crospovidone USP and Aerosil 200 was obtained from CDH New Delhi. Nitric acid, Wheat starch I.P., Magnesium stearate IP and Talc IP was obtained from Institute of pharmacy Bundelkhand University Jhansi.

\section{METHODS:}

Preparation of Acid Modified Starch: $1000 \mathrm{gm}$ of wheat starch was blended with $100 \mathrm{ml}$ of $0.8 \mathrm{~N}$ Nitric acid. The mixture was stored at ambient condition $\left(29^{\circ} \mathrm{C}\right)$ for $24 \mathrm{~h}$ with occasional stirring. The liquid was separated from solid and the wet cake was washed with distilled water to eliminate the traces of acid. The process of washing was continued till the $\mathrm{pH}$ of washing was equal to that of distilled water ${ }^{5}$.

Preparation of Co-Processed Excipients: DCP (25\% of the expected yield of the dry Acid modified starch), was thoroughly mixed with the washed wet cake of acid modified starch (prepared earlier). The wet mass was dried at a temperature less than $75^{\circ} \mathrm{C}$ till the moisture content of powder was dropped to approximately $2 \% \mathrm{w} / \mathrm{w}$. The excipients blend was passed through a \#30 sieve and the yield of dried granules was recorded. The granules were stored in a sealed polyethylene bag till further use.

Preparation of Drug-Excipients Blend: Drug was sieved through a \# 60 sieve. The dry powder was sequentially mixed with Aerosil $200(3 \mathrm{mg})$ to improve the flow of the drug particles. The drug-excipients blend was lubricated with talc $(3 \mathrm{mg})$, magnesium stearate (1.5 $\mathrm{mg}$ ), sodium saccharine (6 mg), and crosspovidone (12 $\mathrm{mg}$ ) and mixed them properly.

Preparation of Drug (Acetaminophen) Tablet: Coprocessed excipient containing $75 \% \mathrm{w} / \mathrm{w}$ of treated starch and $25 \% \mathrm{w} / \mathrm{w}$ DCP was blended with drugexcipient blend (acetaminophen, sodium saccharine Aerosil, talc and magnesium stearate,) in a ratio of 70 to 30. Four percentage of Crosspovidone was used as an extra granular disintegrant. The blend ready for compression was stored in a sealed polyethylene bags. The mixture was compressed on a single punch tablet machine.

TABLE 1: FORMULATION CHART

\begin{tabular}{cccc}
\hline & & \multicolumn{2}{c}{ Ingredients $(\mathbf{m g})$} \\
\cline { 3 - 4 } Formulation Code & Acetaminophen & $\mathbf{( m g})$ & \multicolumn{2}{c}{ Co-Processed Excipient } \\
\cline { 3 - 4 } & & D.C.P & Starch \\
\cline { 3 - 4 } F1 & 120 & 7.72 & 146.78 \\
F2 & 120 & 15.45 & 139.05 \\
F3 & 120 & 23.18 & 131.33 \\
F4 & 120 & 30.90 & 123.61 \\
F5 & 120 & 38.63 & 115.88 \\
F6 & 120 & 46.35 & 108.15 \\
F7 & 120 & 54.08 & 100.43 \\
F8 & 120 & 61.82 & 92.73 \\
\hline
\end{tabular}

\section{Material Properties:}

Angle of repose: The fixed funnel method was used to determine the angle of repose. The funnel was mounted over a base free of vibration. The funnel height was adjusted in such a fashion that the tip of funnel was $3 \mathrm{~cm}$ above the pile tip. Sample was allowed to fall freely on stationary base. The angle of repose was determined by measuring height of the cone of sample. Grading of the flow was done as per USP. The following equation was used to compute angle of repose $(\alpha)^{6}$;

$\tan \alpha=$ height of powder pile / radius of base 
Angle of repose of materials is depicted in Table 2.

Determination of water content: The moisture content was determined by drying $20 \mathrm{gm}$ of each sample in a vaccum oven at $110 \pm 2{ }^{\circ} \mathrm{C}$ for $2 \mathrm{~h}$. The percentage loss in weight was recorded as moisture content ${ }^{7}$. Moisture content of materials is depicted in

\section{Table 2.}

Measurement of densities: Tapped density was measured by using a digital tester (USP II, Electrolab, Model no- ETD- 1020). The loose bulk density was determined for each sample by pouring
$20 \mathrm{gm}$ of the sample at an angle of $45^{\circ}$ through a glass funnel into a $20 \mathrm{ml}$ glass measuring cylinder with $25 \mathrm{~mm}$ diameter. Compressibility index (I) and Hausner's ratio $(\mathrm{H})$ were computed by the following equations:

$$
\begin{gathered}
\mathrm{I}=\mathrm{VO}-\mathrm{Vf} / \mathrm{Vo} ; \\
\mathrm{H}=\mathrm{VO} / \mathrm{Vf}
\end{gathered}
$$

Vo is volume before tapping, Vf is volume occupied by a sample of the powder after tapping procedure ${ }^{6}$. The observed values of materials are depicted in Table 2.

TABLE 2: RESULTS OF EVALUATED PARAMETER FOR EXCIPIENTS

\begin{tabular}{cccccc}
\hline Evaluated parameter & Starch & DCP & Co-processed diluent (3:1) & Acid treated Starch & Drug-excipients blend \\
\hline Angle of repose & 42 & 31 & 30 & 27 & 32 \\
Moisture content & 13 & - & 2 & 0.34 & - \\
Bulk density (gm/cc) & 0.48 & 0.70 & 0.60 & 0.65 & 0.67 \\
Tap density (gm/cc) & 0.611 & 0.92 & 16 & 0.80 & 17 \\
Carr's index (\%) & 25 & 21 & 1.13 & 1.18 & 18 \\
Hausner's ratio & 1.33 & 1.20 & & & 1.20 \\
\hline
\end{tabular}

\section{Tablet Properties: (table 3 and 4)}

Uniformity of Weight: The uniformity of weight test is run by weighing 20 tablets individually and collectively and calculating the average weight of one tablet, and comparing the individual tablet weight to the average. The tablets meet the Indian Pharmacopoeia (1996) weight uniformity test if not more than two of the individual weights deviate from the average weight by more than the percentage shown in table 3 and none deviates by more than twice that percentage. Here, twenty tablets were weighed individually and the average weight was determined. Percentage deviation was calculated and checked for weight variation.

\section{TABLE 3: WEIGHT VARIATION TOLERANCES FOR TABLETS}

\begin{tabular}{cc}
\hline Average Weight & Percentage deviation \\
\hline $80 \mathrm{mg}$ or less & 10 \\
More than $80 \mathrm{mg}$ but less than & 7.5 \\
250 & 5 \\
$250 \mathrm{mg}$ or more & \\
\hline
\end{tabular}

Fineness of dispersion: Two tablets were dispersed in $100 \mathrm{ml}$ of water. The dispersion was passed through a screen with a nominal aperture of $710 \mu \mathrm{m}$. When the dispersions were passed through $710 \mu \mathrm{m}$, no particles were retained on sieve.
Disintegration: Disintegration test of all tablets was carried out in USP disintegrating tester (Electrolab, ED$2 \mathrm{~L})$. Disintegration of six tablets was measured at $37^{\circ} \mathrm{C}$ 6 .

Crushing Strength: Crushing strength of each tablet was determined using Dr. Schleuniger crushing strength tester (Pharmatron, tablet tester 8M).

Drug Content Uniformity: The test for uniformity of content of single-dose preparations is based on the assay of the individual contents of active substance(s) of a number of single-dose units to determine whether the individual contents are within limits set with reference to the average content of the sample. The preparation complies with the test if each individual content is 85 to 115 per cent of the average content.

The preparation fails to comply with the test if more than one individual content is outside these limits or if one individual content is outside the limits of 75 to 125 per cent of the average content. If one individual content is outside the limits of 85 to 115 percent of the average content but within the limits of 75 to 125 percent, repeat the determination using another 20 dosage units. 
The preparation complies with the test if not more than one of the individual contents of the total sample of 30 dosage units is outside 85 to 115 per cent of the average content and none is outside the limits of 75 to 125 per cent of the average content ${ }^{8}$.

Method: Five tablets of each formulation were taken and amount of drug present in each tablet was determined. Each tablet was crushed separately and distilled water (about $50 \mathrm{ml}$ ) was added to extract the drug. Volume was made up to $100 \mathrm{ml}$ with distilled water, and then filtered through Whatmann filter paper no. 42, diluted and analyzed in UV spectrophotometer at $234 \mathrm{~nm}$.

Hardness: Hardness of tablet is defined as the force applied across the diameter of the tablet in order to break the tablet. The resistance of the tablet to chipping, abrasion or breakage under condition of storage, transportation and handling before usage depends on its hardness. Hardness of the tablet is determined by using hardness tester like Pfizer/ Monsanto. Hardness test was conducted for three tablets from each batch using Monsanto hardness tester ${ }^{9}$.

Tablet friability: Friability of the tablets was determined in Roche friabilator. The tablets were carefully dedusted prior to testing. Tablets corresponding to $6.5 \mathrm{gm}$ weight were charged in the friabilator. The drum was rotated for $4 \mathrm{~min}$. Loose dust was removed from the surface and the weight of tablet was recorded. A maximum mean weight loss from three samples of not more than $1 \%$ is considered acceptable ${ }^{9}$.

TABLE 4: OBSERVED PHYSICAL PARAMETERS OF FAST DISSOLVING TABLETS

\begin{tabular}{|c|c|c|c|c|c|c|}
\hline Formulation Code & Drug content & Weight Variation & Hardness $\left(\mathrm{Kg} / \mathrm{cm}^{2}\right)$ & $\begin{array}{c}\text { Wetting Time } \\
\text { (sec) }\end{array}$ & $\begin{array}{c}\text { Disintegration } \\
\text { (sec) }\end{array}$ & Friability (\% loss) \\
\hline F1 & $97 \pm 0.12$ & \pm 0.58 & $3.80 \pm 0.12$ & $25 \pm 0.35$ & $38 \pm 1.43$ & \pm 0.32 \\
\hline $\mathrm{F} 2$ & $96 \pm 0.5$ & \pm 0.47 & $3.62 \pm 0.56$ & $15 \pm 0.27$ & $25 \pm 1.12$ & \pm 0.55 \\
\hline F3 & $96 \pm 0.28$ & \pm 0.89 & $4.16 \pm 0.40$ & $9 \pm 0.16$ & $18 \pm 0.98$ & \pm 0.82 \\
\hline F4 & $95 \pm 0.19$ & \pm 0.92 & $4.29 \pm 0.21$ & $14 \pm 0.28$ & $21 \pm 1.02$ & \pm 0.93 \\
\hline F5 & $97 \pm 0.23$ & \pm 0.53 & $4.68 \pm 0.31$ & $13 \pm 0.23$ & $10 \pm 0.78$ & \pm 0.89 \\
\hline F6 & $96 \pm 0.21$ & \pm 0.88 & $3.92 \pm 0.33$ & $11 \pm 0.18$ & $22 \pm 1.09$ & \pm 0.88 \\
\hline F7 & $98 \pm 0.11$ & \pm 0.73 & $3.80 \pm 0.34$ & $10 \pm 0.16$ & $32 \pm 1.17$ & \pm 0.84 \\
\hline F8 & $99 \pm 0.10$ & \pm 0.84 & $4.81 \pm 0.36$ & $11 \pm 0.12$ & $36 \pm 1.16$ & 0.86 \\
\hline
\end{tabular}

Thickness: The crown thickness of individual tablets may be measured with a micrometer. The total crown thickness may be measured with sliding caliper scale. Tablet thickness should be controlled within $\pm 5 \%$ variation of standard value. Thickness was measured using Vernier Calipers. Ten individual tablets from each batch were used and the average thickness was calculated ${ }^{10}$ (table 5).

\section{TABLE 5: THICKNESS OF THE TABLET}

\begin{tabular}{ccc}
\hline Formulation code & Diameter $(\mathbf{m m})$ & Thickness $(\mathbf{m m})$ \\
\hline F1 & 9.0 & $3.6 \pm 0.10$ \\
F2 & 9.0 & $37 \pm 0.11$ \\
F3 & 9.0 & $3.9 \pm 0.11$ \\
F4 & 9.0 & $4.0 \pm 0.08$ \\
F5 & 9.0 & $3.7 \pm 0.13$ \\
F6 & 9.0 & $3.9 \pm 0.05$ \\
F7 & 9.0 & $3.8 \pm 0.10$ \\
F8 & 9.0 & $3.8 \pm 0.12$ \\
\hline
\end{tabular}

RESULTS AND DISCUSSION: Starch exhibit poor flow and poor compressibility. Hence, it is not widely used as a diluent in direct compression. Starch can be modified by adopting chemical means and used as a diluent in direct compression ${ }^{5}$. The characterization of powder flow was done as per the recently introduced chapter on powder flow in USP. The flow was graded as excellent, good, fair and passable for angle of repose $25-30^{\circ}, 31-35^{\circ}, 36-40^{\circ}$ and $41-45^{\circ}$ respectively. The angle of repose of starch, acid treated starch and co-processed excipient was $42^{\circ}, 27^{\circ}$ and $30^{\circ}$ respectively ${ }^{6}$.

Accordingly, starch exhibited passable flow, i.e. the powder may hang up in hopper. The Carr's index which is a measure of the flowability and compressibility of a powder. The lower the Carr's index of a material, the better the flowability and Hausner's ratio provides an indication of the degree of 
densification ${ }^{11}$. Low Hausner's ratio of co-processed excipients and acid treated starch indicate better compressibility than starch (See Table 1). Starch exhibited poor to passable flow $(\mathrm{I}=21-25 \%$ and $\mathrm{H}=$ 1.35-1.45). Dicalcium phosphate exhibited fair flow. The drug-excipients blend exhibited good flow ( $\mathrm{I}=11$ $15 \%$ and $H=1.12-1.18)$. There are two primary requirements for directly compressible diluents, i.e. good flow and good compactability ${ }^{12}$.

The use of direct compression is limited in industry due to flowability, content uniformity and tablet ability problems. Flowability and tablet ability are of concern in high dose tablet while content uniformity is of concern in low dose tablet. Generally small size drug particles are used in direct compression. Hence, poor flow and poor content uniformity may be seen. The problem of poor flow of drug can be addressed by mixing of $0.5 \%$ glidant with drug (first step of glidant addition) and remaining $0.5 \%$ glidant and other ingredients were mixed in drug-glidant mixture (second step of glidant addition) ${ }^{3}$.

All formulation showed weight variation throughout in the range of \pm 0.47 to \pm 0.92 . No significant difference in the weight of individual formulations from the average value was observed and variations were within the range. The fast dissolving tablets showed uniform thickness throughout, in the range of 3.6 to $4.0 \mathrm{~mm}$ and diameter $9.0 \mathrm{~mm}$. The friability was below $1 \%$ for all formulations which is an indication of good mechanical resistance of tablet. The hardness of different formulation was found to be between 3.62 \pm 0.40 to $4.81 \pm 0.36 \mathrm{~kg} / \mathrm{cm}^{2}$ indicating good mechanical strength. The drug contents in the fast dissolving tablets were also within the limit of $95 \pm 0.19$ to $98 \pm 0.11$. All tablets disintegrated in less than $1 \mathrm{~min}$.

CONCLUSION: The co-processed excipients containing acid modified starch and DCP exhibited improved flowability as measured by angle of repose, compressibility index and Hausner's ratio.
The lower moisture content could be the reasons for improved flow of co-processed diluents. Acetaminophen tablets exhibited acceptable crushing strength and quick disintegration into primary particles. The salient points of the co-processed diluents are low moisture content, low cost, ease of availability of raw materials, quick disintegration of tablets and possibly regulatory acceptance.

ACKNOWLEDGEMENT: The authors are thankful to Green Pharma for providing gift samples.

\section{REFERENCES:}

1. Bradoo R, Shahani S, Deewan B, Sudarshan S. Fast dissolving drug delivery system. J Am Med, Assoc India, 2001; 4 (10): $27-$ 31.

2. Sreenivas SA, Dandagi PM, Gadad AP, Godbloe AM, Hiremath SP, Mastiholimath VS. Oro-dispersible tablets: New-fangled drug delivery systems - A review. Indian J Pharm Educ Res, 2005; 39(4): 177-181.

3. Gohel MC, Jogani PD. A review of processed directly compressible excipients. J Pharm Pharmaceutics Sci., 2005; 8(1): 76-93.

4. Block LH, Moreton RC, Apte SP, Wendt RH, Munson EJ, Creekmore JR, Persaud IV, Sheehan C, Wang H. Co-processed Excipients, Pharmacopeial Forum. 2009; 35(4).

5. Ranley J. Starch and its derivatives, Fourth edition, 1968: 30652.

6. United States Pharmacopoeia, XXIX, NF XIV. The United States Pharmacopoeial Convention Inc., 2006.

7. Yu L, Christie G. Measurement of starch thermal transitions using differential scanning calorimetry. Carbohydrate Polymers, 2001, 46: 179-84.

8. European Pharmacopoeia, Council of Europe, Pharmaceutical Technical Procedures, Third Edition, 1997: 133.

9. United States Pharmacopoeia, XXIX, NF XIV. The United States Pharmacopoeial Convention Inc., 2006: 3046.

10. N. Zajc, A. Obreza, et al. Physical properties and dissolution behavior of Nifedipine/ Mannitol solid dispersion prepared by hot melt method. Int. J. Pharm., 2005, 29:51-58.

11. Odeku O, Picker-Freyer K. Characterization of acid modified dioscorea starches as direct compression excipients. Pharm. Dev. Tech., 2009; 14: 259-70.

12. Madhusudan B., Rambhau D. Studies on sulphamethoxazole solid dispersions and there tablets. Indian J. Pharma. Sci., 2003; 233-238.

13. Seager $\mathrm{H}$. Drug-delivery products and Zydis Fast dissolving dosage form. J Pharm Pharmacol, 1998; 50: 375-382. 